\title{
Analysis of Pragmatic Failures and Strategies for Teaching Chinese as a Foreign Language
}

\author{
Xihang Yang* \\ College of Foreign Language, Guizhou University, Guiyang 550025, Guizhou Province, China \\ *Corresponding author: Xihang Yang, 498071867@qq.com
}

Copyright: ( $) 2022$ Author(s). This is an open-access article distributed under the terms of the Creative Commons Attribution License (CC BY 4.0), permitting distribution and reproduction in any medium, provided the original work is cited.

\begin{abstract}
Cross-cultural communication has become an essential course for international students. As foreign students have different cultural backgrounds and languages, pragmatic failures are inevitable for them when communicating in Chinese, thus resulting in unpleasant communication. In order to effectively reduce pragmatic failures, it is necessary to analyze the problems that arise in the process of teaching Chinese as a foreign language and determine the causes. This research is separated into three aspects. Firstly, with the support of the theory of pragmatics and by analyzing the life and learning of foreign students, it can be appreciated that the pragmatic failures of foreign students in using Chinese for communication are very much detailed in the teaching of Chinese as a foreign language ${ }^{[1]}$. Secondly, after arranging and analyzing these corpora, the reasons for the pragmatic failures of foreign students are determined. Finally, aiming at the causes of pragmatic failures, corresponding countermeasures and teaching suggestions are proposed. The conclusion drawn from this research is that pragmatic failures occur due to various factors, some of which are essential factors that cannot be changed. This requires effort from both Chinese language teachers and students in the teaching of Chinese as a foreign language to lessen the occurrence of pragmatic failures.
\end{abstract}

Keywords: Cross-cultural communication; Pragmatic failure; Teaching Chinese as a foreign language

Online publication: January 20, 2022

\section{Introduction}

Teaching Chinese as a foreign language is a cross-cultural teaching activity conducted to guide students in communication. Its function is not only to impart Chinese knowledge to foreign students, but also to teach them how to use Chinese to reduce pragmatic failures.

On the one hand, as most of the teachers are native Chinese, it is difficult to have a comprehensive understanding of western culture. As a result, concealed communicative mistakes may occur in the teaching process, which would have a considerable impact on the whole process. Therefore, analyzing and studying pragmatic failures in the teaching of Chinese as a foreign language is a perpetual research subject in academic circles.

\section{Cross-cultural pragmatic failures}

Pragmatic ability can be explicated as the ability to use language to communicate correctly. It can be separated into two parts: expression and understanding. In order to ensure the adequacy of language, the language user must learn to use the language agilely and reasonably for specific language environment, while attaching importance to social and cultural elements. In cross-cultural communication, pragmatic 
failures are often deemed more serious than linguistic errors, such as speech and grammar, as these mistakes may offend the other party and affect interpersonal relationships.

\subsection{Understanding pragmatic failures}

Most misunderstandings are caused by lacing the speaker's intentions or extrapolating the contextual meaning of the discourse in language communication. Therefore, the right end of communicative intention is the key to successful communication. Otherwise, pragmatic failure or communication failure may occur.

Pragmatic failure is the failure to understand the communicative or implicit information transmitted by the speaker through a certain utterance. In cross-cultural communication, pragmatic failure is a crucial element leading to communication failures. In fact, pragmatic ability does not describe as precisely and particularly as linguistic elements, such as grammar and vocabulary. Furthermore, the use of language is highly dependent on contextual condition, which is universal and complex.

\subsection{Pragmatic failures in the teaching of Chinese as a foreign language}

Most of the topics that foreign students can learn during Chinese lessons are related to their lives. The corpus of pragmatic errors collected in this paper is mainly based in the classroom environment, and a small part includes pragmatic failures encountered when communicating with foreign students. Since pragmatic failure is the correct discourse in the wrong situation, this article will provide the corresponding context when analyzing the corpus. The following section analyzes the causes of pragmatic failures, including Chinese phonetics, vocabulary, grammar, society, and body language. The examples are the wrong sentences that students have uttered ${ }^{[2]}$.

\subsubsection{Pragmatic failure caused by phonetics}

In many countries, the languages used do not carry tone. When students learn Chinese, tone is a huge problem, especially when trying to pronounce correctly with one voice but with four tones. In Chinese, the meaning of a word is recognized by its tone, and the tone is irreplaceable in sentences. The part that is usually emphasized will be re-read, and students usually make mistakes because they have re-read a certain word.

\section{Example 1.}

我想嫁人了。

A Thai student was sitting alone in a playground with a look of despair on her face. When her friend, who is a Chinese, asked her why she was sad, she answered, “我想嫁人了.” Hearing the answer, her friend did not understand why she wanted to get married. The Thai student added, “我的家人都在泰国, 我很想 念他们.” It was then that her friend realized that the foreign student said, “家人,” rather than “嫁人.”

\subsubsection{Pragmatic failure caused by vocabulary}

Chinese vocabulary can be separated into two categories: basic vocabulary and fixed vocabulary. Many words imply pragmatic functions in communication ${ }^{[3]}$. In Chinese, people can choose different words according to different contexts when they communicate, but students are not skilled enough. Therefore, mistakes may occur in word selection.

\section{Example 2.}

A：我男朋友真好，感谢上帝。 
Example 2 is a sentence uttered by a Russian student during a class. However, this kind of sentence is very strange to the Chinese. It is a good thing to have a good boyfriend, but to the Chinese, it is strange as of why one would wish to thank God for it. The phrase "thank God" is an expression that reflects being fortunate; however, the Chinese rarely use this idiom.

\subsubsection{Pragmatic failure caused by grammar}

Each language has its own grammar rules. In order to learn Chinese, it is necessary to learn Chinese grammar by heart. The part of foreign language grammar that is similar to Chinese grammar allows foreign students to grasp quickly. However, when encountering a part different from their native grammar, foreign students are prone to pragmatic failure.

\section{Example 3.}

我没有钥匙, 进去不能。

An American student was just standing at the door of his room, seemingly without any intention to go in. A student, who was passing by, asked him why he was standing there. The American student replied as shown in Example 3, in which he meant to say, “I do not have the key, I cannot go in." “不能” means “no." This literally means that the international student is not allowed to enter the room. Therefore, the phrase “不能” is incorrect in this case. The proper expression that would reflect the intention of the student is “进 不去.”

\subsubsection{Pragmatic failure caused by the society}

Generally, when Chinese people receive gifts, they would not open those gifts in front of the guests. When they receive things, Chinese would tend to say, “让您破费了” or “这怎么好意思呢.” On the other hand, when Westerners receive gifts, they usually open those gifts in front of the guests and then express their gratitude. Therefore, when foreign students give something to another person, if the other party does not open the gift immediately, it would seem that the receiver is blaming the giver for bringing gifts or the receiver does not take the gift seriously.

\subsubsection{Pragmatic failure caused by body language}

Body language can be separated into facial expressions, physical touch, gestures, manners, spatial distance, and so on.

For example, the "okay" gesture means "good" in Europe, America, and China; however, in some Mediterranean countries, it means homosexuality; in France, it means "zero" or "nothing"; in Japan, the gesture signifies money. Therefore, the differences in nonverbal cross-cultural communication should also be emphasized.

\section{Reasons for cross-cultural pragmatic failures}

In cross-cultural communication, the national cultural norms and social norms are usually assumed as the standard for interpreting and evaluating people's behaviors. Behaviors often lead to communication failures and generate large psychological gaps or social distance, thus leading to pragmatic failure. It can be said that pragmatic problems are obstacles to the smooth progress of cross-cultural communication. There are many reasons why foreigners experience pragmatic failures in Chinese. 


\subsection{Subjective causes}

\subsubsection{Interference of culture of the native language}

Culture includes nationality. Each culture has its own unique style and connotation. Each culture has a set of value system, moral concepts, psychological orientation, norms, and behavior patterns. These factors regulate the use of language by every nation. When foreigners use Chinese, they tend to rely excessively on expressions that conform to the cultural habits of their mother tongue to directly fit in or over-generalize.

For example, during a sport event, a teacher ran 100 meters and won the championship. A student complimented the teacher by saying, “老师, 你跑的像一只狗!”. This is apparently a disrespect. In the west, dogs are often regarded as family members, but the student did not know that dogs in Chinese reflect negative cultural tendencies, mostly for their intentions.

\subsubsection{Contradiction of cultural identity}

When foreigners learn Chinese, they need to adjust their cultural attitudes to face the Chinese cultural environment. However, no matter how much they try to, they tend to rely on their own national culture and supplement it with the Chinese culture. At times, when foreign students learn Chinese, they do understand the cultural background. However, in expressing, they still tend to make pragmatic mistakes, which shows that the potential culture in the mother tongue is dominating. Many western students tend to say, “你吃了 吗?”, since it is awkward to say hello.

\subsubsection{Limitation of foreign students' language skills}

In cross-cultural communication, when foreigners are unable to express their meaning smoothly, they often translate from their mother tongue directly, sometimes with exaggerated expressions, and from time to time, they blurt out words in their own mother tongue in a hurry. This results in various language biases. When their language skills do not reach the level where they can freely express, students consciously or unconsciously focus on the ideology, neglecting the pragmatic aspects.

\subsection{Objective causes}

\subsubsection{Flaws in the teaching of Chinese as a foreign language}

Zhao Yuanren once said, "Language is a set of habits. The learning of foreign languages is to develop a special habit." Many teachers who are teaching primary Chinese tend to first use a single initial or final, focus on tone learning, and then combine with the text and context. The learning of initials and finals is easy for foreign students to master, but the tone is difficult for them. Many students who have passed HSK (Hanyu Shuiping Kaoshi) Level 6 still cannot overcome this issue. Therefore, the four-tone voice teaching is important. Teachers should turn off the voice at the beginning, at each initial and final.

\subsubsection{Tolerance for pragmatic failures}

In communication, native speakers have a set psychological impression of the language level of the second language user in consideration of the lack of cultural knowledge. Even if the other party has a pragmatic failure, violates various pragmatic principles, or does not comply to the pragmatic rules, the set psychological impression creates a form of tolerance during communication. This kind of tolerance makes pragmatic failures undetectable. 


\section{Ways to avoid cross-cultural pragmatic failures}

By analyzing the pragmatic failures of foreign students, it can be concluded that pragmatic failures occur in cross-cultural communication due to the influence of culture, psychology, and teaching. Foreigners have learnt a lot from the Chinese people from these mistakes. If they do not know that they have pragmatic mistakes, they would not be able to grasp the correct pragmatic rules in Chinese. However, in the process of teaching Chinese to foreign learners, teachers should always remember not to disregard these common problems to correct students in time. Several countermeasures have been proposed for the pragmatic failures of foreign students.

\subsection{Combine language teaching and cultural teaching}

Language is an important aspect of culture and the primary carrier of culture. Language and culture are closely related and inseparable. The cultural background of a nation has created the pragmatic rules of each national language. Although students are learning the language, they are not always exposed to the Chinese culture. Therefore, in order to use Chinese proficiently, it is necessary to master the pragmatic rules of Chinese and understand the Chinese culture ${ }^{[4]}$.

The crux of the mistake is the difference in cultural background. Hence, culture teaching must be an integral part of language teaching. Both language teaching and cultural teaching are complementary and indispensable ${ }^{[5]}$.

\subsection{Strengthen the cultivation of pragmatic ability}

Theory must be put into practice in order to be verified. If a language is not used in real communication, it is not possible to know whether someone has mastered the knowledge. Teachers should set feasible contexts in classrooms. It is convenient for students to have a dialogue with each other as teachers can correct them in time. After classes, teachers can give assignments in such a way as to encourage the students to utilize certain words or sentences effectively in particular situations. As part of an activity, students can be asked to go out of the classroom and try to communicate with a Chinese student, and then obtain feedback for class review, so as to check whether they are able to apply the language suitably in a specific environment.

\subsection{Improve the teaching materials}

A good teaching material should be able to play a role in keeping with the times. For foreign students, the purpose of learning Chinese is to be able to apply it to communication. Therefore, the teaching materials need to be conversational and practical. It is necessary to update the contents in textbooks along with the times. For example, “你好” is usually used when meeting someone for the first time; however, foreign students use it anytime and anywhere. The materials for teaching foreign students should be updated, so that the Chinese language used by foreign students can keep pace with the times.

\section{Conclusion}

Chinese is by far the most spoken language across the world. With the increasing number of foreigners learning Chinese, the language will become another important communication tool for foreigners. Communication is not restricted to among people of the same nation, but with globalization, coming into contact with foreigners is without doubt increasingly common. Cross-cultural communication involves culture and language. In view of different languages and cultural backgrounds, pragmatic failures are inevitable in communication, resulting in various problems, including cultural conflicts. Teaching Chinese as a foreign language is not only to teach Chinese vocabulary or grammar, but also imparting the pragmatic 
rules and improving students' communication skills in Chinese.

\section{Disclosure statement}

The author declares that there is no conflict of interest.

\section{References}

[1] Ma R, 2019, Proceedings of 2019 8th International Conference on Social Science, Education and Humanities Research (SSEHR 2019), 2019: A Study on the Transformation of College English Teachers into TCFL Teachers, Francis Academic Press, UK, 321-325.

[2] Chen K, 2017, Proceedings of the 2017 7th International Conference on Mechatronics, Computer and Education Informationization (MCEI 2017), December 2017: Pragmatic Acquisition and Teaching Chinese as a Foreign Language, Atlantis Press. DOI: 10.2991/mcei-17.2017.46

[3] Yin Y, Chai H, 2021, A Study on Cognitive Pragmatic Strategies of Political Euphemism from the Perspective of Criticism. Foreign Language Studies in Northeast Asia, 2021(02): 50-57. DOI: 10.16838/j.cnki.21-1587/h.2021.02.009

[4] Ying X, 2019, Proceedings of 2019 9th International Conference on Social Science and Education Research (SSER 2019), 2019: Research on the Application of "Blended" Teaching Mode in Teaching Chinese as a Foreign Language, Francis Academic Press, UK, 128-132.

[5] Wang D, 2011, A Study on Cross-cultural Adaptation of International Students from Africa and Asia in Chengdu's Universities, University of Electronic Science and Technology of China. https://kns.cnki.net/KCMS/detail/detail.aspx?dbname=CMFD2011\&filename=1011194482.nh 